\title{
AC 2007-954: ENHANCING VIBRATION AND CONTROLS TEACHING WITH REMOTE LABORATORY EXPERIMENTS
}

\section{Gangbing Song, University of Houston}

Gangbing Song is an Associate Professor in the the Department of Mechanical Engineering at the University of Houston and Director of the Smart Materials and Structures Laboratory.

\section{Claudio Olmi, University of Houston}

Claudio Olmi is a Graduate Student in the Department of Electrical and Computer Engineering at the University of Houston

\section{Richard Bannerot, University of Houston}

Richard Bannerot is a Professor of Mechanical Engineering at the University of Houston. He is a registered engineer in the state of Texas. 


\title{
Enhancing Vibration and Controls Teaching with Remote Lab Experiments
}

\begin{abstract}
This paper describes the remote laboratory experiments and demonstrations developed in the Department of Mechanical Engineering at the University of Houston to enhance students' learning of vibrations control and their knowledge of smart materials. Two intelligent vibrating structures utilizing smart materials to control and damp structural vibrations have been integrated into an internet based virtual laboratory. The students are now able to control the experimental variables through a virtual instrument, created through the commercial virtual lab software LabView, from places and times convenient to them. By using a remote laboratory students are able to take turns sharing a single experimental set-up and their educational experience is enriched while reducing the costs to the student and to the university. Student survey responses following remote demonstrations of the experiments are very positive. Over $90 \%$ of all responses indicated that the experiments and demonstration were either "Effective" or "Very Effective." Additionally, the students expressed the unanimous desire for more remote laboratories. Based on this positive experience, a remote laboratory based course has been proposed in the Department of Mechanical Engineering.
\end{abstract}

\section{Introduction}

Conventional laboratories have become increasingly costly for universities. The increased costs of equipment, materials, and support personnel, coupled with time, space, and enrollment constraints, have made the addition of novel laboratory components to existing lecture courses very difficult ${ }^{1}$. However, with recent advances in technology and the development and acceptance of the internet as a viable medium for high-speed data transmission, a potential replacement to the traditional university experimentation has emerged - the remote laboratory. By housing a single or limited number of experimental set-ups on site at the university and allowing students to control and collect data from the on-site hardware through the internet, universities have been able to diversify their laboratory course selection while controlling costs, space, and time commitments and enriching the students' academic experiences.

This paper describes and presents evidence of the effectiveness of a number of remotely controlled experiments at the University of Houston created to enhance the teaching of vibrations and controls in predominately lecture courses in both mechanical and civil engineering. The remote experiments also integrate the use of emerging smart materials to enrich the students' understanding of concepts presented in lecture. Through remotely controlled demonstrations and laboratory experiments, students were able to connect principles taught in class to real-world, observable phenomena without having to enter a traditional laboratory. Student response to these remote labs has been positive and a clear student demand for more remote labs and demonstrations has been presented. 
Though engineering controls lecture courses teach processes by which to manage and regulate real-world objects and require students to gain an understanding of how real systems are designed to interact ${ }^{2}$, there existed no laboratory course at the University of Houston in which students would be able to apply the strategies learned in class to real-world phenomena. The introductory course in vibrations and controls was purely theoretical, with no opportunities for the students to test their knowledge or to troubleshoot real-world problems. According to recent studies ${ }^{4}$ traditional engineering lecture courses tend to alienate a significant portion of students whose learning styles are visually, active, or experience oriented, leaving these students with an incomplete comprehension of the course material. Furthermore, development of conventional laboratory components of the course required quantities of bulky, expensive equipment, hiring qualified personnel, and a large, dedicated laboratory space.

However, due to the recent expansion of the internet and advances in commercial technology, remote laboratories have increasingly become a feasible solution to various laboratory courses suffering the same dilemmas. Subsequently, controls and vibrations in-classroom demonstrations were developed in the Smart Materials and Structures Laboratory (SMSL) at the University of Houston to also serve as remotely controlled mini-experiments. By integrating commercially available smart materials, such as piezoceramic patches and shape memory alloy (SMA) wires, into the experiments, the SMSL was able to reduce their cost. With the support of industrial sponsors a number of mini-experiments are in development for commercialization.

\section{Background to Smart Materials}

The most innovative component of these remote demonstrations/experiments is the utilization of different kinds of smart materials, i.e., materials that are considered to be "responsive." The produced response is often the conversion of one form of energy to another in useful quantities. For example, a SMA returns to a trained shape from a deformed state when heated above its transformation temperature. While there are many kinds of smart materials, the demonstrations and experiments described in this paper focus on the use of SMAs, piezoceramics, and MagnetoRheological (MR) fluids.

\section{Magneto-Rheological Fluids}

Magneto-Rheological fluids have the special property of changing their viscosity in the presence of a magnetic field, thickening from a motor oil-like consistency to a near solid in fractions of a second. An MR fluid is composed of nano-scale, magnetizable metal particles suspended in a non-conductive carrier fluid, such as oil. In the absence of a magnetic field, the particles are free flowing and act Newtonian or nearly so. However, in the presence of a magnetic field the dipoles of the particles align, forming small chains of particles across the two potentials, as illustrated in Figure 1.

As the magnitude of the magnetic field through the fluid increases, the strength of the particle chains formed across the fluid also increases. On a macro-level, the observed effect is a change in the effective viscosity of the fluid, causing resistance against any movement through the fluid. Since the magnitude of the viscosity change is directly related to the change in magnetic field strength, an MR fluid is a reliable, easily controlled alternative to mechanical damping methods. 

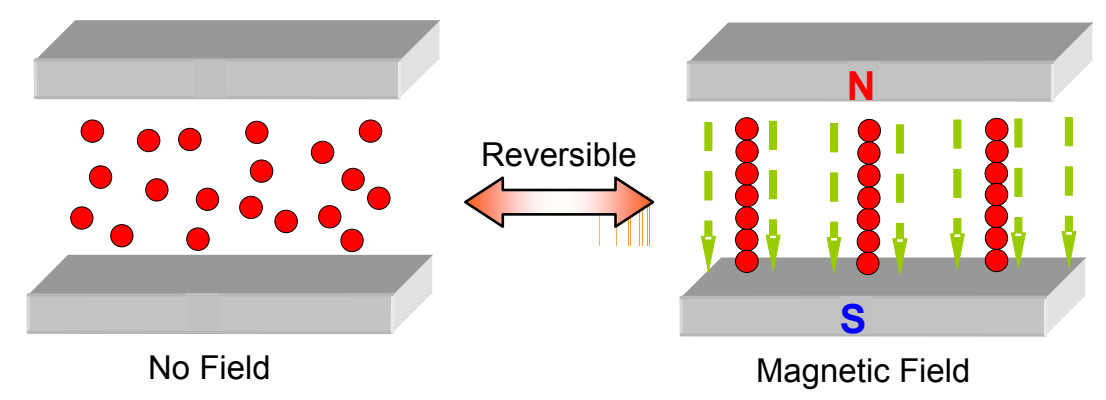

Figure 1: Magnetic Field Aligns Particles in MR Fluid

\section{Shape Memory Alloy}

Shape Memory Alloy (SMA) materials are metallic alloys that have the special property of being able to return to a pre-determined, or "trained," shape from a deformed state when the material is heated above its transformation temperature. A number of alloy types are known to exhibit the Shape Memory Effect (SME), or the ability to revert to a trained shape when heated, including gold-cadmium and nickel-titanium, or nitinol. The SME follows from the changes in atomic crystal structure that the alloy forms at different temperatures.

For example, above its transformation temperature, Nitinol exists with a strong cubic packed Austenite structure. However, at lower temperatures a Martensite structure is formed in which any four contiguous atoms form a weak structure resembling a parallelogram in two dimensions. These martensite structures form a row of parallelograms "tilting" uniformly in a single direction. The next row of martensite structures tilts in the opposite direction, as pictured in Figure 2, creating the twinning effect, where the rows appear to be symmetrical, or twinned, through a plane of symmetry.

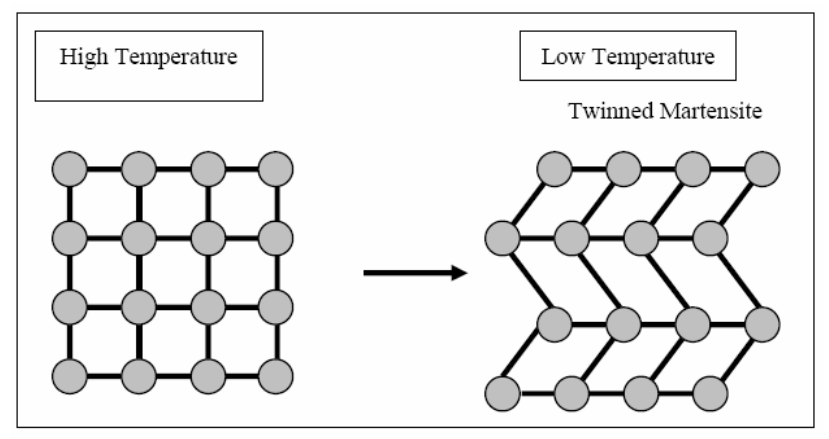

Figure 2: Twinned Martensite Structure

The weakness of the martensite allows the material to be easily deformed by mechanical forces.

When a mechanical shearing force is applied to the material at a low temperature, the crystals are 
re-aligned such that the rows all tilt in the same direction in a process called de-twinning (illustrated in Figure 3).

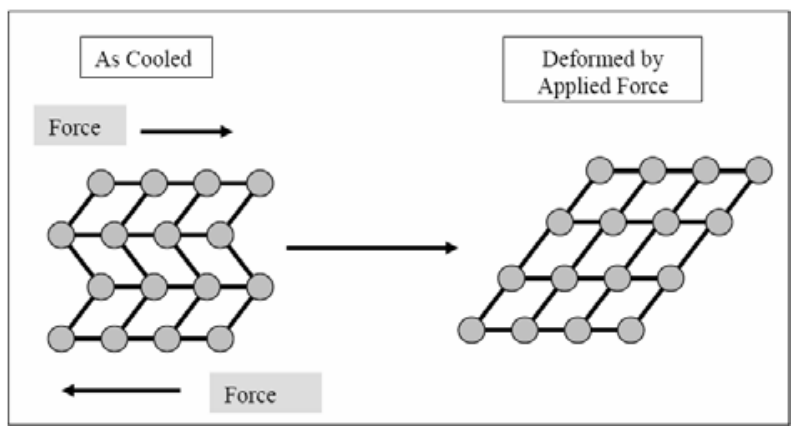

Figure 3: De-Twinning of Martensite Formation at Low Temperatures

At low temperatures, then, the material behaves like a normal, malleable metal alloy. However, the SME takes place when the alloy is heated above this transformation temperature which causes the atomic crystal structure of the atoms to change from martensite to austenite. As the atomic crystal structure changes, so, too, does the overall shape of the material, reverting to a pre-determined shape created by training the material above the transformation temperature over time. Due to the training, the overall austenite form is maintained through cooling and deformation. The process of deformation and transformation for an SMA spring is illustrated in Figure 4. If any resistance is encountered during the transformation process, the material itself can exert extremely large forces to counter.

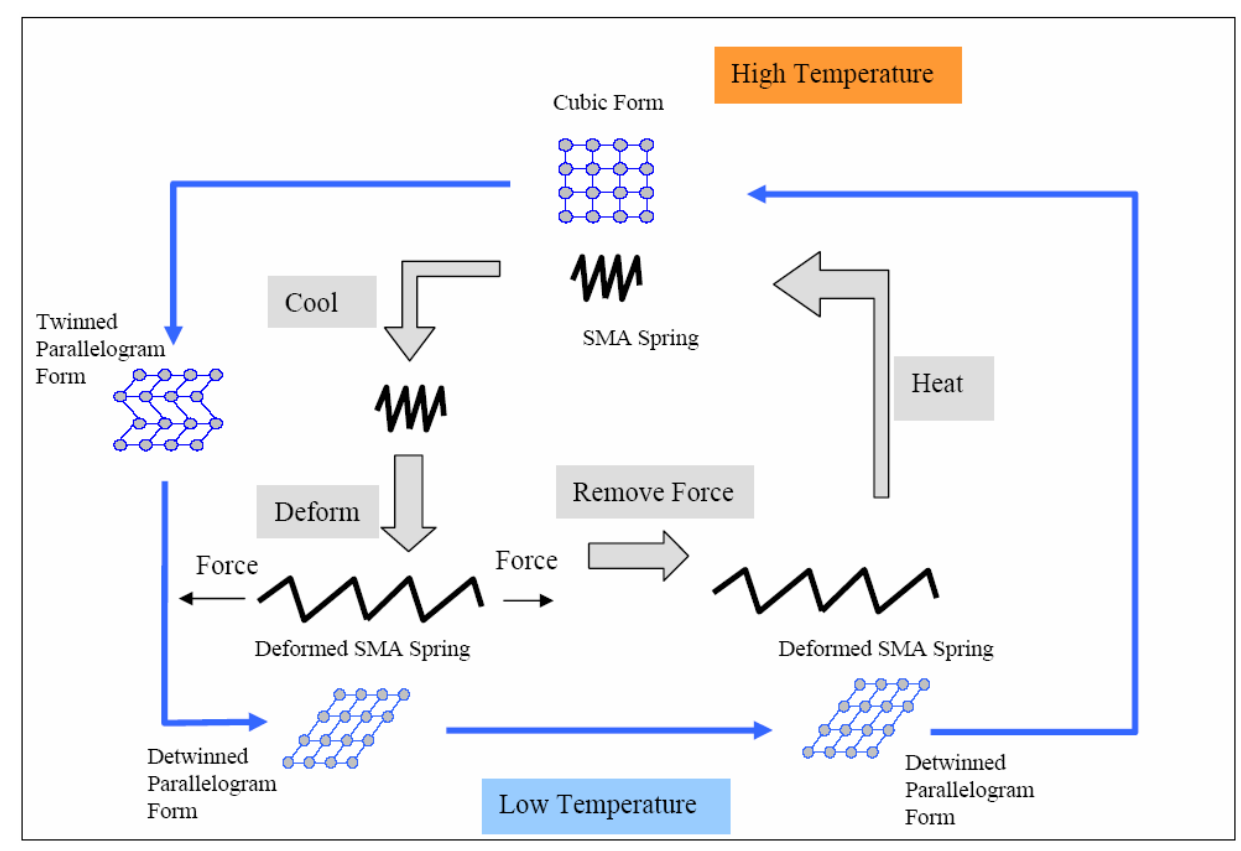

Figure 4: Macro and Micro Views of SMA Spring Deformation and Transformation 


\section{$\underline{\text { Piezoceramics }}$}

Piezoelectric (or simply "piezo") materials exhibit the piezoelectric effect (PE), creating an electrical charge when a mechanical stress is applied and, conversely, mechanically deforming when an electrical field is present. The PE occurs in ferroelectric materials whose crystalline structure has no center of symmetry, such as barium titanate and lead zirconate titanate (PZT). Ferroelectric ceramics become piezoelectric after a process of electrical poling. Weiss domains, groups of electrical dipoles with parallel orientation, are randomly oriented in raw piezoceramic materials (See Figure 5(a)).

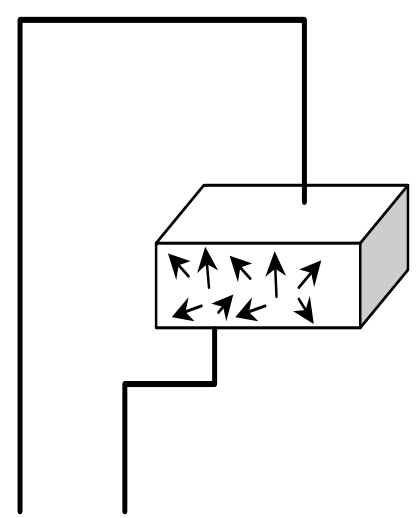

(a)

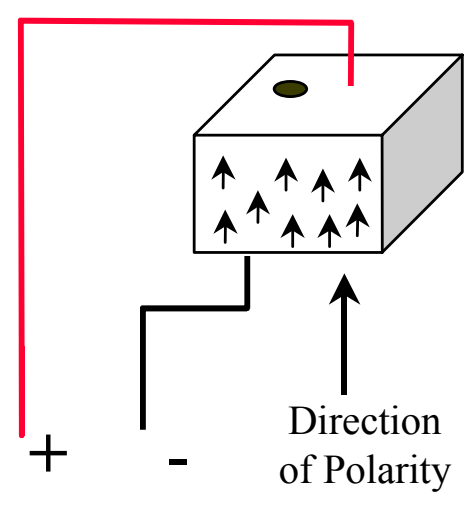

(b)

Figure 5: Piezoceramic Poling Process: Before (a) and After (b)

To pole the piezoceramic, a strong electric field $(>2000 \mathrm{~V} / \mathrm{mm})$ is applied to the heated piezoceramic material, inducing the material to expand along the axis of the field and contract perpendicular to the axis (Figure 5(b)). After the material cools and the field is removed, the Weiss domains roughly remain in alignment. As a result, the material now has its own polarity which can be degraded by exceeding the mechanical, thermal, and electrical limits of the material. Subsequently, there is a growth in the direction parallel to the polarization and a contraction in the direction perpendicular to the polarization. The macro observation of the electro to physical deformation is illustrated below in Figure 6, where a small piezo patch is surface bonded to a cantilevered beam structure. When the applied voltage is opposite that of the piezo, the piezo expands laterally, bending the beam upward (Figure 6(a)). Conversely, when the voltage is the same as the polarity, the piezo contracts laterally, pulling the beam downward (Figure 6(c)). When no voltage is applied, the beam returns to its normal position (Figure 6(b)). 


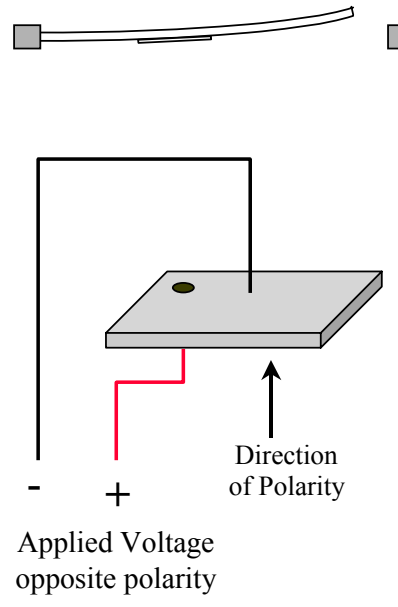

(a)

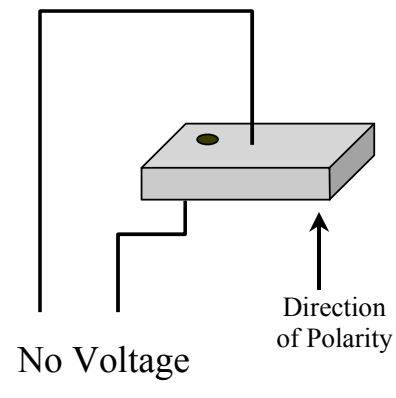

(b)
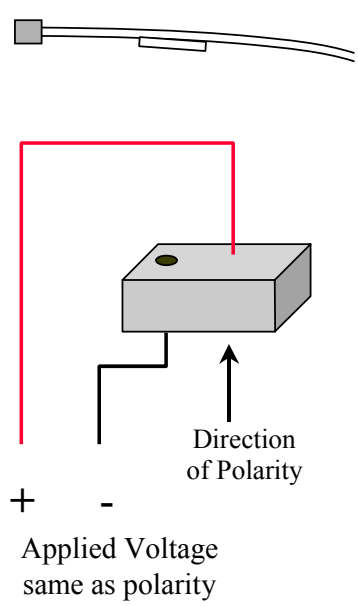

(c)

Figure 6: Deformation of Piezoceramics due to Applied Voltage

Conversely, by utilizing the physical-deformation-to-electric-field-change property, piezoceramics can also be used as sensors. The inverse piezoelectric effect is illustrated in Figure 7 in the same cantilevered beam set-up as before.

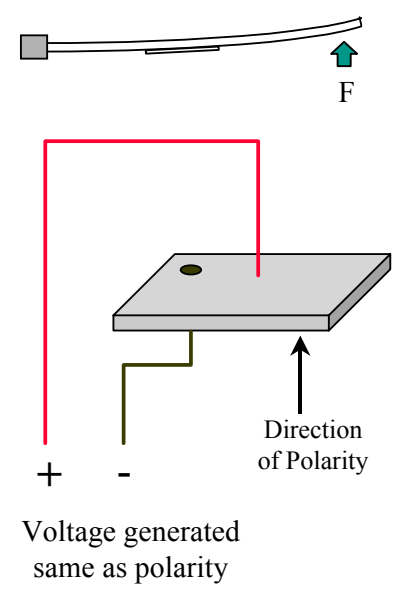

(a)
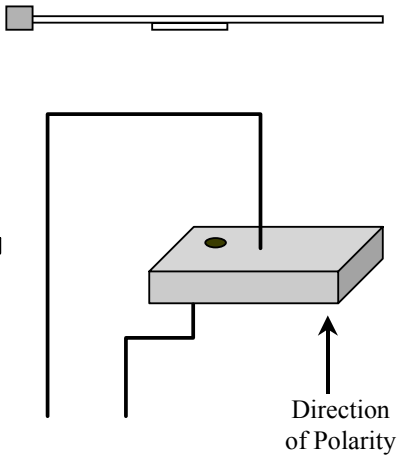

No voltage generated

(b)
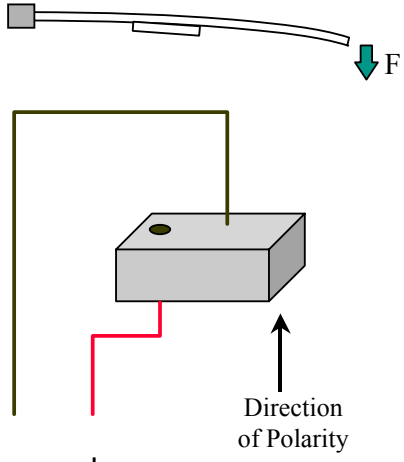

$-\quad+$

Voltage generated opposite polarity

(c)

Figure 7: Inverse Piezoelectric Effect

Here, when the beam is bent by a force upward in Figure 7(a), the piezo is stretched and the induced voltage across the electrodes is opposite the polarity of the material. Similarly, when the beam is bent downward by a force in Figure 7(c), the piezo is compacted, inducing a voltage across the electrodes in the same direction as the material polarity. Again, when no deformation occurs, no voltage is generated (in Figure 7(b)). 


\section{Experimental Hardware and Set-Up}

\section{$\underline{\text { Smart Model Building }}$}

The first remote experiment used a Smart Model Building (SMB) ${ }^{8}$, a multi-level frame structure constructed with PZT patches (the piezo sensor/actuator), surface bonded to the base. These PZTs induce vibrations in the structure, provide active damping of the structural vibration, and act as sensors for the displacement of the structure walls. A schematic diagram and a photograph of a prototype of the SMB are presented in Figure 8.

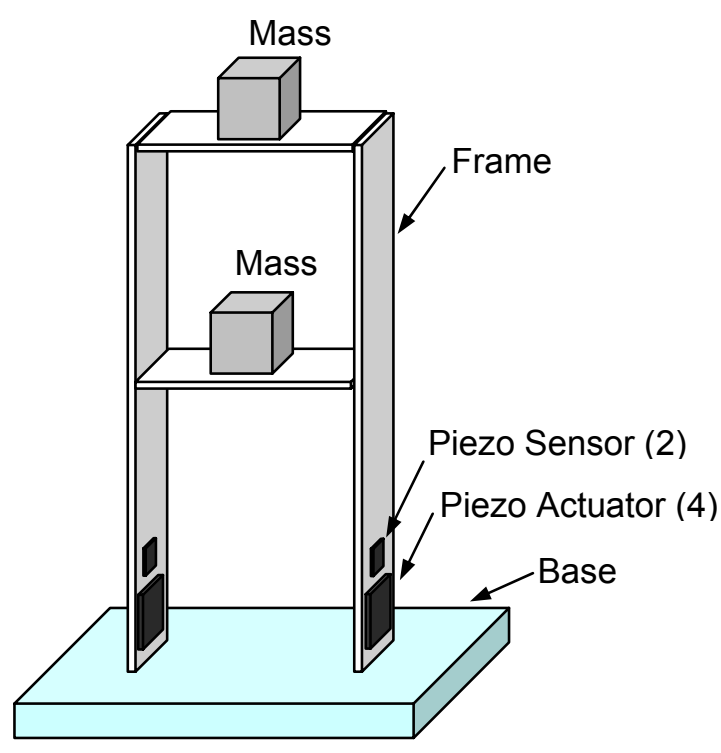

(a)

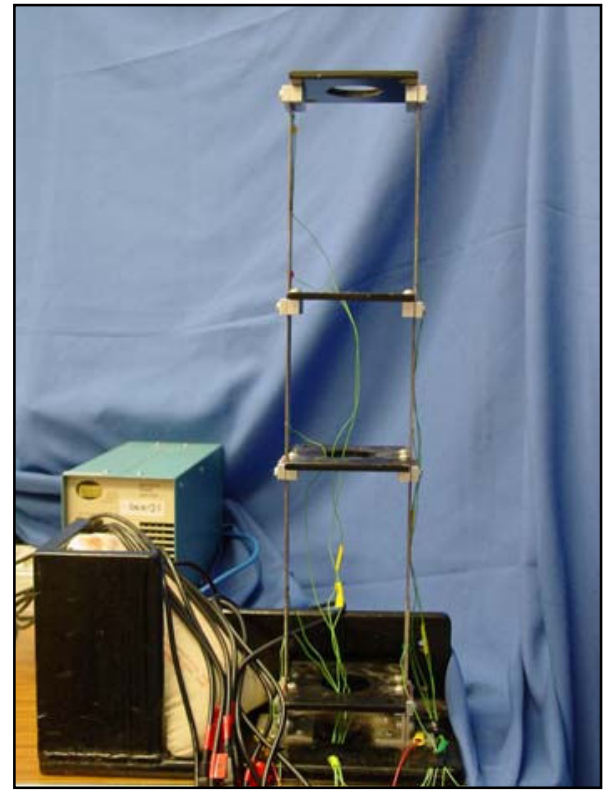

(b)

Figure 8: Smart Model Building

The steel frame is flexible enough to conduct some structural vibration. Masses can be added to the structure to change its dynamic properties. The frame is mounted on a heavy steel base which is further weighed down by a sand bag to prevent the vibrating structure from tipping when in use. As noted earlier the PZT patches are surface bonded to the frame near the base of the structure. Two pairs of large PZT patches are used as actuators, one pair for excitation of the structure to vibrate and the other pair for active control of the structural vibrations. Four smaller PZT patches are used as sensors for feedback for the active vibration control. The PZT actuator and control patches can be linked to a function generator or a PC to use custom control algorithms to damp the vibrations. 


\section{$\underline{\text { Smart Vibration Platform }}$}

A second remote experiment developed was the Smart Vibration Platform (SVP), used to demonstrate principles of vibrations control. The SVP is pictured in Figure 9. A three-sided, steel frame is mounted on a rigid base which is attached to a flat surface. The flexible, vertical sides of the steel frame allow the structure to vibrate from side to side. A rotary motor with mass imbalance is mounted on top of the steel frame, inducing the structure to vibrate when the motor is running. Two techniques can be employed to control the damping of the structure: one uses an MR fluid and the other uses SMA wires. In the first case a steel tongue attached to the upper platform dips into a narrow MR fluid reservoir damper which is mounted to the rigid base. An electromagnet is placed around the MR fluid reservoir damper such that the terminating ends of the electro-magnet "clamp" the MR reservoir damper. When the electro-magnet creates a magnetic field through the MR fluid damper, the MR fluid increases in viscosity, making it difficult for the tongue to move, damping the vibration of the structure. In the second case two sets of SMA wire braces are stretched diagonally across the steel frame, forming an " $\mathrm{X}$ " shape. On the ends of each set of SMA braces, alligator clips are attached to allow current to flow through the wires and induce electrical heating. As the wires are heated, they contract, stiffening the structure, illustrating the effects of stiffness on the damping ratio of the overall structure.

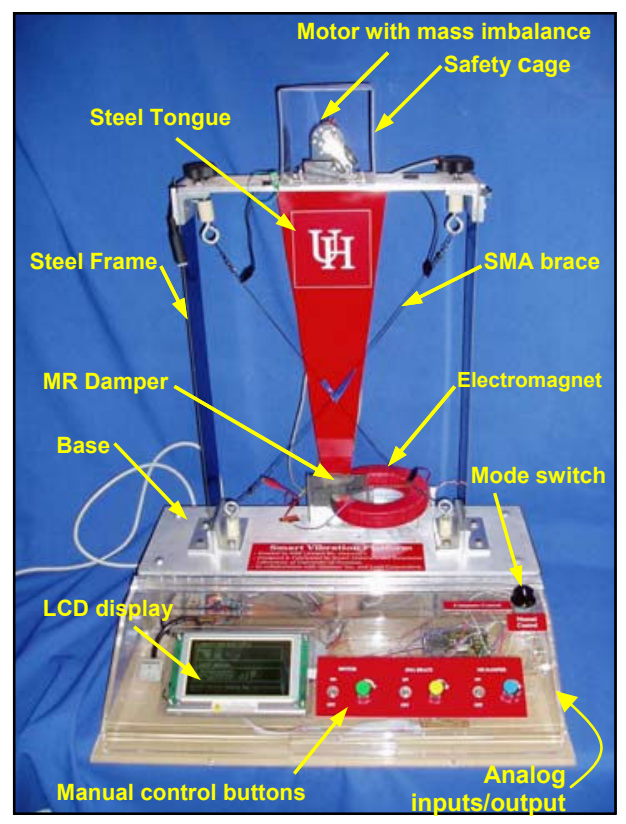

Figure 9: SVP Platform ${ }^{11}$

Power is provided to the electro-magnet, the SMA wire braces, and the rotary motor from a power supply encased in a plastic sub-base, which also contains a microcontroller allowing for computer controlled demonstrations, analog input/output ports for demonstration and feed-back control with a PC link (See Figure 10.), manual control buttons, and an LCD user display. A piezoceramic sensor mounted on the steel frame allows the display to export data about the system through the output ports on the side of the display to a computer. By linking the SVP 
display to a data control board and a PC through the analog ports, the SVP display can be used as an experiment demonstrating closed-loop control with a real-time control system.

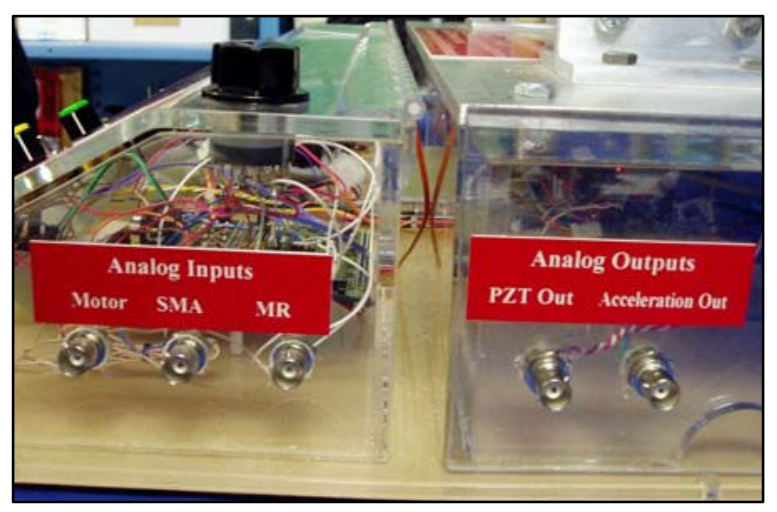

Figure 10: Analog Input/Output Links for PC

\section{Internet Based User Interface}

Numerous exploratory experiments ${ }^{5,6,10}$ and studies ${ }^{7,9}$ have found that remote or asynchronous laboratories can be as effective as traditional laboratories in helping students to understand course material and to develop experimental skills. Increasing interest in the creation of remote laboratory experiments has lead to the commercial development of software that allows instructors to design and customize their own internet interface without having to develop and program from scratch ${ }^{10}$. For the experiments described in this paper, the LabView development software by National Instruments was used to create the Virtual Instruments (VI) through which students control the actual experimental hardware remotely through the internet. This virtual representation of real interaction with actual hardware, allows the student to control certain variables of the experiment and to collect real-time data being generated by the experiment running remotely on the university campus. The LabView software package tools control the hardware, develop graphical interfaces, and publish the creations on the internet as platform independent ActiveX components, reducing the time spent by the instructor in creating an internet interface and increasing the ease of use by the student. The interactions with the Labview created VIs in the remote lab are summarized in Figure 11.

Students gain access to the remote lab web page on the internet, through the web server that hosts the LabView interface package. The instructor can customize the parameters controlling the students' access to the hardware unit, e.g., the number of allowed users, the number of allowed viewers, and session length.

When the internet connection to the web server is established, the users will be given the VI and web cam feeds in their browsers, shown in Figure 12(a). Multiple users are allowed to access the web page simultaneously, but only one is allowed control of the experiment at a time. The user right-clicks in the VI window to request control of the experiment. If no one else is using the hardware, the user is granted control. If the hardware is already in use, up to five additional users are allowed to view the experiment in progress. Additional requests to view the page are 
denied. When the current user relinquishes control of the experiment, one of the viewers is allowed to request control of the hardware. In the current configuration, users are not confined to a certain lab session length, though in the future time limits for control may be established to reduce wait time.

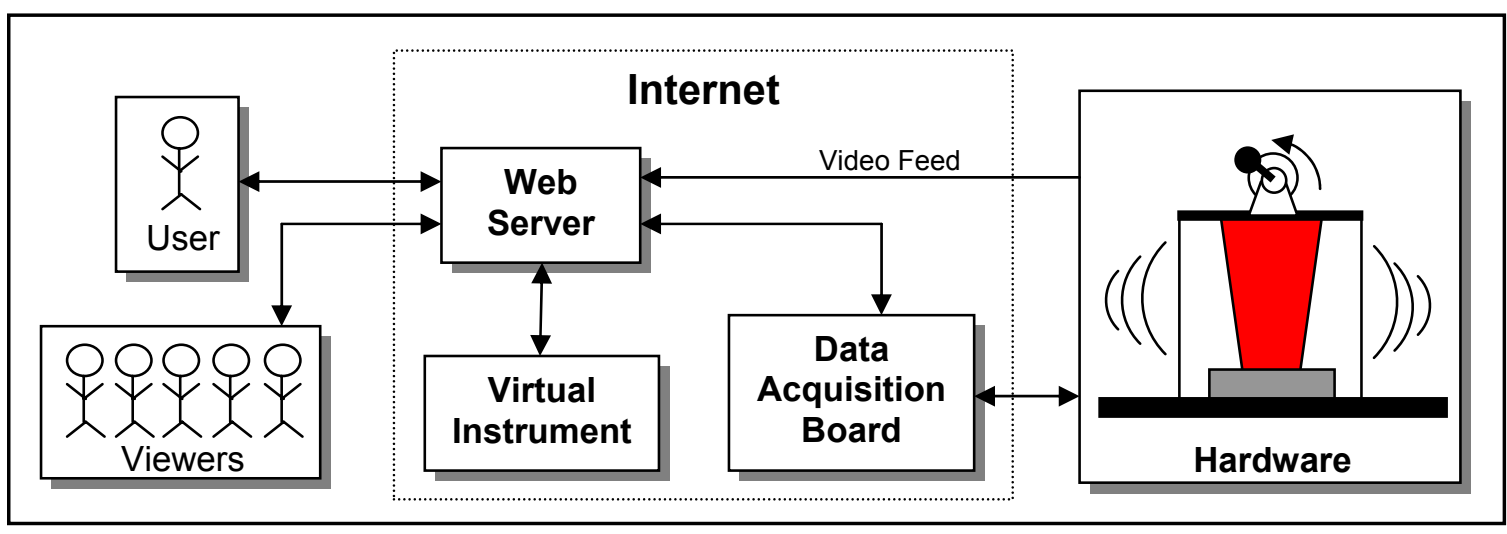

Figure 11: Remote Lab Interactions

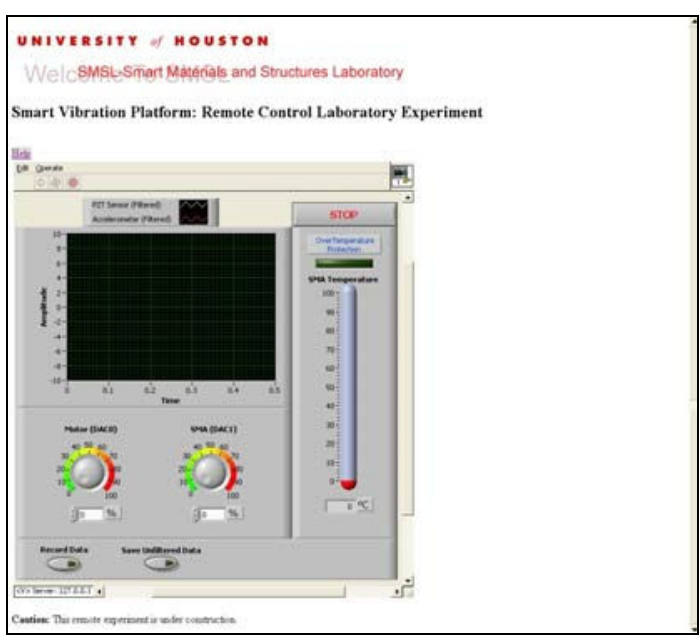

(a)

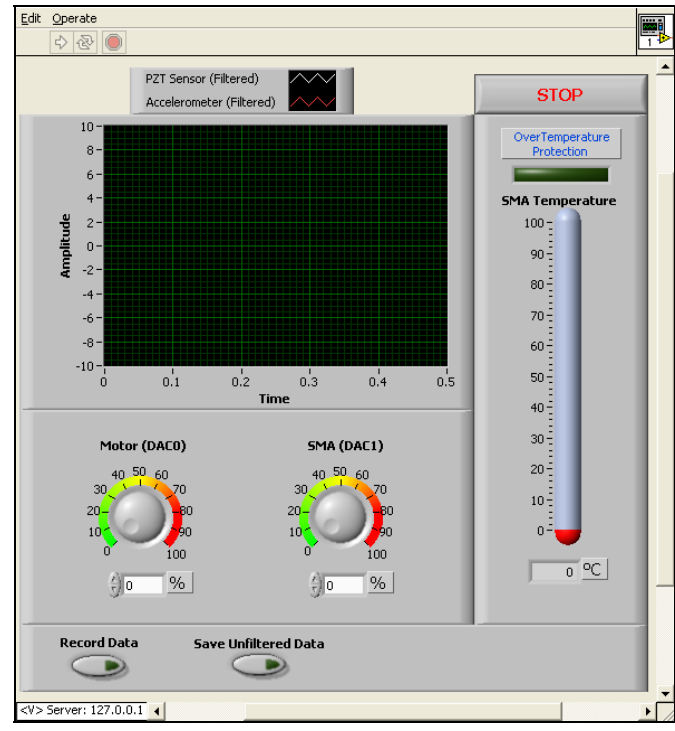

(b)

Figure 12: Remote (a) Lab Browser Window and (b) Virtual Instrument (VI)

Prior to the experiments, students are asked to calculate the expected changes due to specific experimental variable changes, such as changes in modal frequency due to changes to the damping ratio. The VI, shown in Figure 12(b), was designed specifically for the SVP hardware, allowing the user to tune the SMA and motor voltages from 0.0 to 2.049 volts by percentage of 
the full capacity by either entering a percentage in a text field or by turning the graphical dials. For the SMB experiment, students are able to control the voltage patterns used to activate the PZT patches. Due to limitations of the data control board used, the VI was limited to only two controllable variables. The VI then sends the user defined values for the experiment, via the internet, to a data control board on the university campus. The data control board converts the computerized signal and sends the information to the micro-processor built into the experimental hardware through co-axial cables. The experiment then operates under the conditions set by the user.

A number of data elements are collected from the hardware and sent back to the user. The PZT patches at the base of the vibrating platforms are used as sensors to detect displacement and acceleration data, sending the voltage change signals back to the data control board through coaxial cables. The data control board converts the signal and sends the data through the internet back to the VI, which displays the data changes in graphical form to the user. The VI allows the user to not only view the data in real-time, but also to record data for comparison against the students' predicted results. Also, network web cams set-up to record the experiment send a live video feed through a university router to the web page viewed by the users. As such, the user has an immediate visual perspective of the hardware changes to match the data presented in the VI. Two complete remote lab set-ups are pictured in Figure 13.

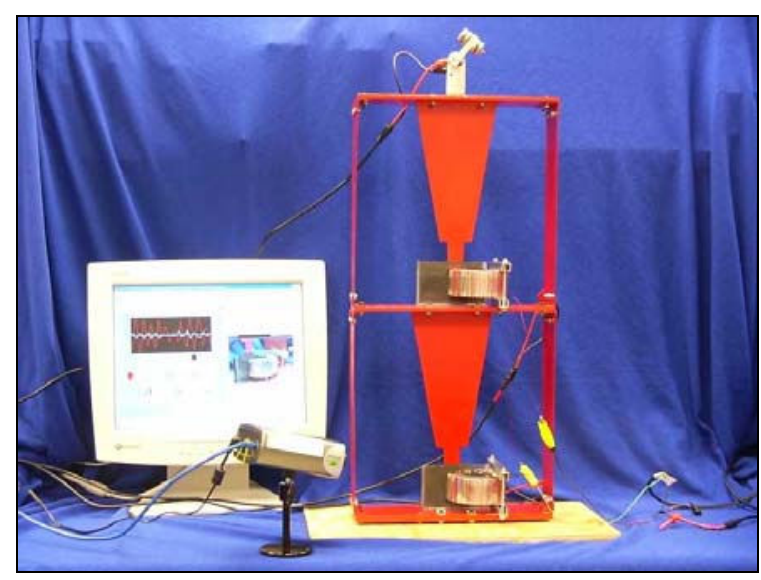

(a)

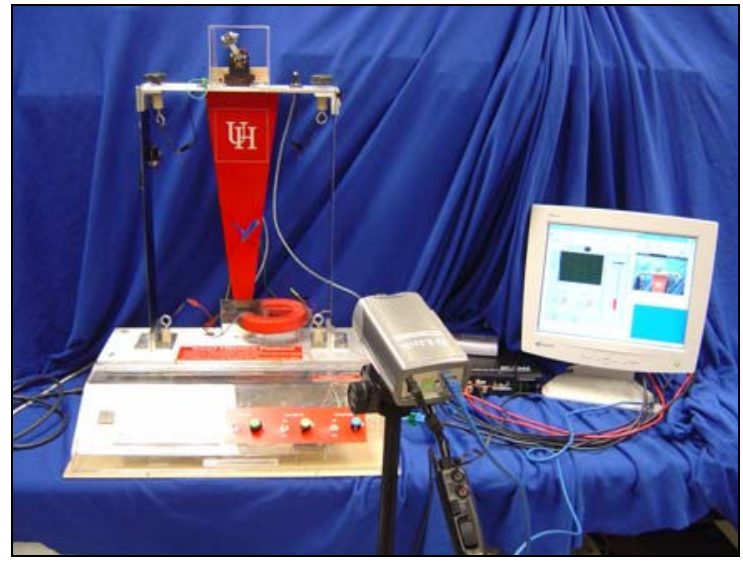

(b)

Figure 13: Complete Remote Lab Set-Ups for (a) Double Layer Building and (b) SVP

\section{Integration into Teaching}

\section{$\underline{\text { Teaching Goals }}$}

The remote laboratories were developed to reduce the costs in laboratory courses and to provide students an opportunity to gain laboratory experience in courses that traditionally did not have laboratory components. The general teaching goals of the remote experiments are as follows: 
1) Bridge the gap between the theories taught in class and the real-world conceptualization by the student

2) Help students to correlate observed phenomena with quantified data.

3) Give students experience using virtual engineering-type tuners and measurement instruments.

4) Allow students access to lab experiments until they understand the concept, freeing them from the time constraints present in traditional labs.

The remote labs described in this paper have a number of additional goals specific to the components used and the courses for which the labs were designed. The specific teaching goals for the remote labs are as follows:

1) Re-enforce students' understanding of the concepts of vibration, resonance, modal frequency, and damping ratio.

2) Provide observable examples of the effects of damping ratio on the resonance of vibrating structures.

3) Provide experience in various active vibration control strategies.

4) Expose students to emerging technology, specifically different types of smart materials.

5) Encourage students to learn more about vibrations control.

6) Motivate students to learn more about smart materials.

\section{$\underline{\text { Student Evaluations }}$}

Anonymous surveys were administered to students following remote demonstrations performed by SMSL personnel on campus during two engineering courses, "Earthquake Engineering" in the civil engineering department and "Vibrations and Controls Laboratory" in the mechanical engineering department (See Figure 14). The student survey summary results for these two classes are given in Table 1.

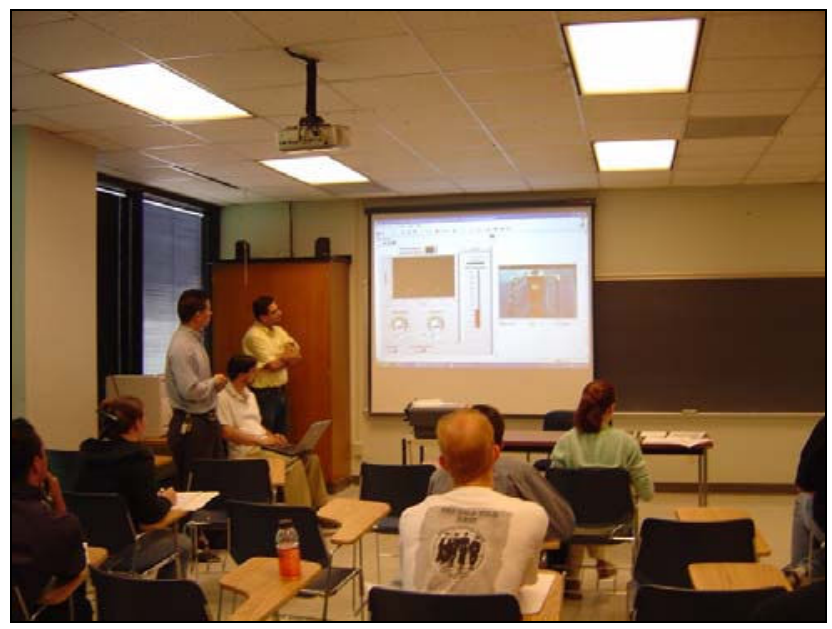

Figure 14: Demonstration of Remote Lab in Vibrations and Controls Class ${ }^{12}$ 
Table 1: Summary of Student Survey Results for Demonstration Classes

\begin{tabular}{|l|c|c|c|c|c|c|}
\hline \multicolumn{1}{|c|}{ Course Information } & $\begin{array}{c}\text { No. of } \\
\text { Students }\end{array}$ & $\begin{array}{c}\text { No. of } \\
\text { Questions }\end{array}$ & $\begin{array}{c}\text { Very } \\
\text { Effective }\end{array}$ & Effective & $\begin{array}{c}\text { Somewhat } \\
\text { Effective }\end{array}$ & $\begin{array}{c}\text { Not } \\
\text { Effective }\end{array}$ \\
\hline $\begin{array}{l}\text { Vibrations and Controls Laboratory, } \\
\text { Mechanical Engineering, April 2005 }\end{array}$ & 11 & 8 & $27 \%$ & $65 \%$ & $8 \%$ & $0 \%$ \\
\hline $\begin{array}{l}\text { Earthquake Engineering, Civil Engineering, } \\
\text { April 2005 }\end{array}$ & 17 & 9 & $57 \%$ & $37 \%$ & $6 \%$ & $0 \%$ \\
\hline Total & 28 & 241 & $46 \%$ & $47 \%$ & $7 \%$ & $0 \%$ \\
\hline
\end{tabular}

Student response to the remote experiment demonstrations was exceptionally positive, with $93 \%$ of all responses to all questions rating the demonstrations as either "Effective" or "Very Effective." There was no response of "Not Effective." For individual aspects of the demonstration, such as the effectiveness to accomplish specific teaching goals, a majority of the students rated the demonstrations as effective, with responses on individual question ranging from $76 \%$ to $100 \%$ as either "Effective" or "Very Effective." Student response distributions for selected, demonstration specific questions are shown in Figure 15.

Effectiveness to Demonstrate Effect of Stiffness on Second Order System

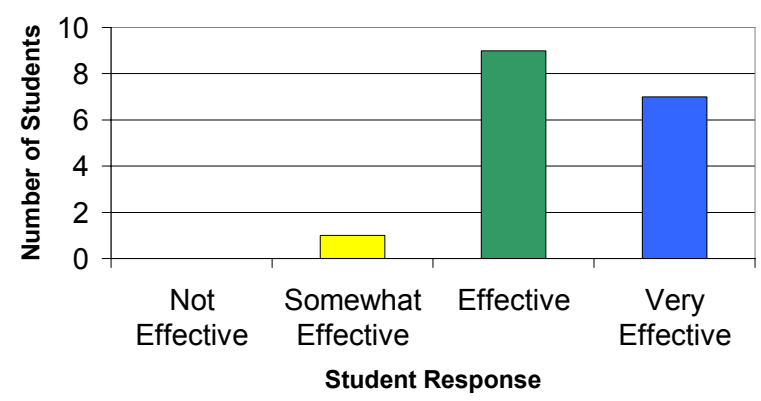

(a) Earthquake Eng'g
Effectiveness to Demonstrate Resonance of a Dynamic System

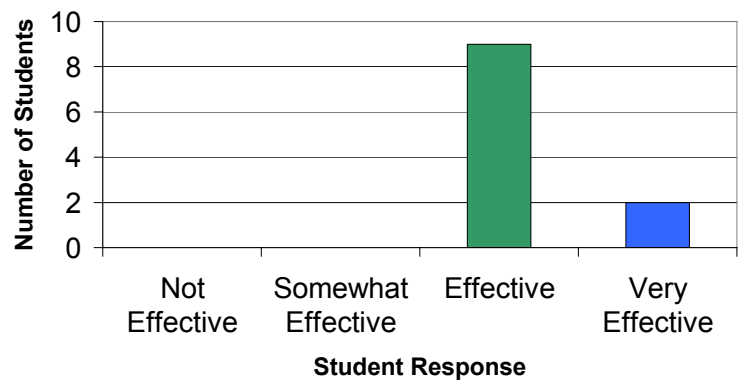

(b) Vibrations and Controls Lab

Figure 15: Student Repsonse Distributions of Selected Demonstration-specific Questions

There were four statements common to both surveys and the students' responds to these are presented in Figure 16. For these four questions, 96\% of the total responses regarding the teaching effectiveness of the remote demonstrations (Figure 16 (a) and (b)) were either "Effective" or "Very Effective." Only two responses were "Somewhat Effective" and there was no response of "Not Effective." Though they were not physically in contact with the experiment, the students overwhelmingly felt that the concepts were effectively illustrated to them by the remote demonstrations. Furthermore, the remote demonstration generated an interest in the course material and in smart materials. In Figure 16 (c) and (d), the interest of the students in having more remote demonstrations and labs is clearly illustrated. All of the student responses indicated a desire to see more remote demonstrations and a need for remote laboratories to be available to them. 


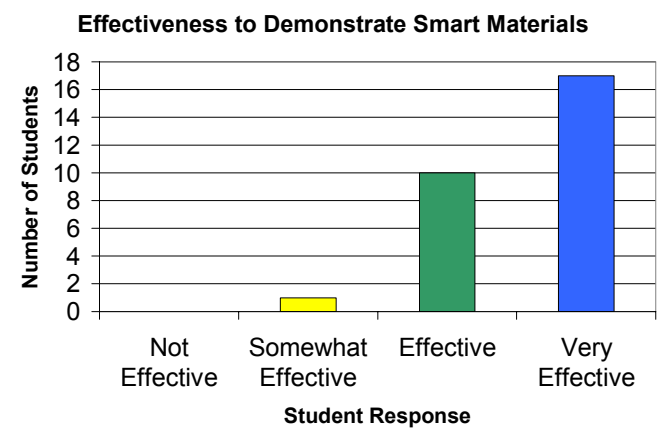

(a)

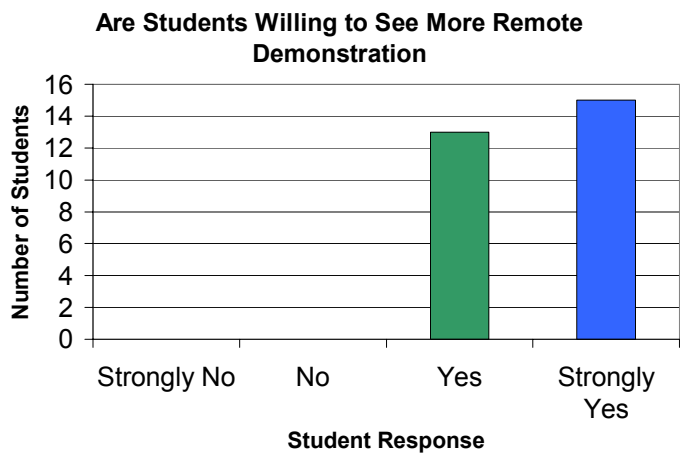

(c)

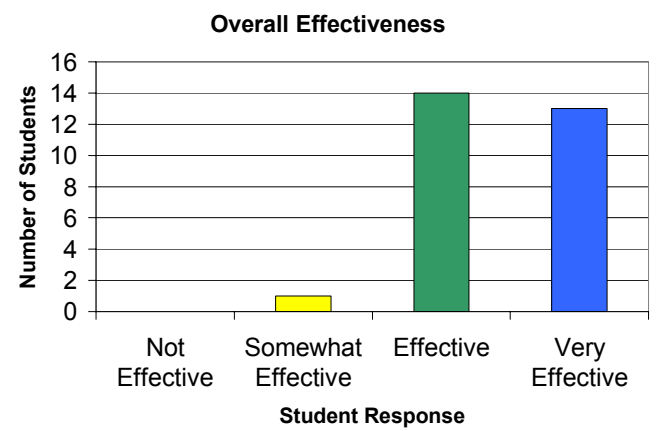

(b)

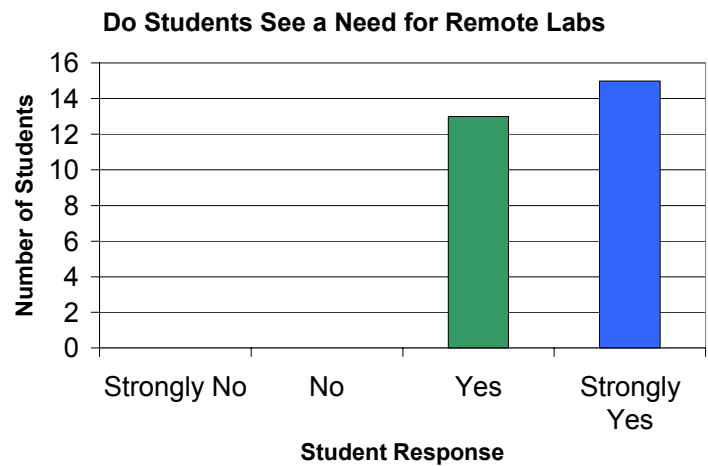

(d)

Figure 16: Student Response Data Evaluating Smart Building Remote Demonstration

\section{Conclusions}

This paper describes the remote laboratories that have been developed and utilized at the University of Houston to enrich a traditional lecture course without adding the costs of a traditional laboratory component and to supplement the experiments in an existing laboratory course. By developing intelligent structures using smart materials and by taking advantage of the LabView remote laboratory development software, the department has been able to provide demonstrable remote laboratory experiments to its students. From these demonstrations, it has been shown that remote laboratories are effective in bridging the gap between theory and practice in traditionally conceptual engineering courses. Furthermore, after viewing these demonstrations, students have expressed both a desire and a need for additional remote laboratory components to their existing courses. From these results, there have been proposals for future remote lab based courses in the mechanical engineering department. 


\section{Future Laboratories}

Additional remote laboratories have been proposed for development in mechanical engineering department. A course entitled "Introduction to Smart Space Structures (ISSS)" has been proposed for upper-level engineering undergraduates and for graduate students in mechanical and aerospace engineering. The course will use a number of remote experiments simulating space structures utilizing smart materials to provide experimental experience with scientific issues ${ }^{13}$ to the student with minimal cost to the university ${ }^{14}$. Specifically, the course will ask students to compare theoretical calculations of different aspects of an intelligent space solar array and compare them to experimental results obtained through the remote lab. Additionally, students will be asked to create MatLab simulation code and SimuLink control systems to be applied to the experiment to give the students real experience in controlling a physical system.

\section{Acknowledgements}

The authors thank the National Science Foundation for providing the grants which made this project possible. Additionally, we would like to thank Quanser Incorporated and Lord Corp. for their industrial support and help in the development of the SVP and the instructors who have kindly allowed these experiments to be presented in their classrooms.

\section{References}

1. Corter, J., Nickerson, J., Esche, S and Chassapis, C. "Remote vs. Hands-On Labs: A Comparative Study," Proceedings of the 34th ASEE/IEEE Frontiers in Education Conference, October 20-23, 2004, Savannah, Georgia.

2. Duan, B., Ling, K.V., Mir, H., Hosseini, M. and Gay, R. K. L. “An Online Laboratory Framework for Control Engineering Courses,” International Journal of Engineering, 2005, Vol. 21, No. 6, pp. 1068-1075.

3. Ellis, G.W., Rudnitsky A.N. and Scordilis, G.E. "Finding Meaning in the Classroom: Learner-Centered Approaches that Engage Students in Engineering," International Journal of Engineering Education, 2005, Vol. 21, No. 6, pp. 1148-1158.

4. Felder, R.M. and Brent, R. "Understanding Student Differences," Journal of Engineering Education, 2005, Vol. 21, No. 1, pp. 166-177.

5. Furman, B.J. and Hayward, G.P. "Asynchronous Hands-On Experiments for Mechatronics Education," Mechatronics, Elsevier Science Ltd, 2002, pp. 251-260.

6. Junge, T.F. and Schmid, C. "Web-Based Remote Experimentation Using a Laboratory-Scale Optical Tracker," Proceedings of the American Control Conference, June 2000, Chicago, Illinois.

7. Lundgren, P., Jeppson, K and Ingerman Å. "Lab on the Web - Looking at Different Ways of Experiencing Electronic Experiments," International Journal of Engineering Education, 2006, Vol. 22, No. 2, pp. 308-314.

8. Mo, Y.L. and Song, G., "A Smart Model Building for Teaching Structures, Dynamics, and Control Related Courses.” NSF Project Report, 2005.

9. Nedic, Z., Machotka, J and Nafalski, A. "Remote Laboratories vs. Virtual and Real Laboratories," Proceedings of the 33rd ASEE/IEEE Frontiers in Education Conference, Nov. 5-8, 2004, Boulder, Colorado.

10. Patrascoiu, N. "Modeling and Simulation of the DC Motor Using MatLab and LabView." International Journal of Engineering Education, Vol. 21, No. 1, 2005, pp. 49-54. 
11. Song, G. "2004 - 05 Progress Report of NSF Project 'Develop a Smart Vibration Platform Experiment'," PowerPoint: NSF Project Progress Report, Project No. 0341143, 2005.

12. Song, G. "Collaborative Research: Phase II development of an innovative multi-functional smart vibration platform, CCLI Phase 2: Expansion Project." NSF Project Progress Report, Project No. 0341143, 2005.

13. Song, G.. Develop an Interdisciplinary Course "Introduction to Smart Space Structures (ISSS)" at University of Houston. NSF Grant Proposal, March 2005.

14. Song, G. "Improving System Dynamics and Vibration Control Courses through Smart Material Demonstrations". University of Houston Internal Proposal, July 2006. 